\title{
Survival analysis with regard to PD-L1 and CD155 expression in human small cell lung cancer and a comparison with associated receptors
}

\author{
YAOLIN XU, GUOYUAN CUI, ZHONGXIU JIANG, NING LI and XIAOYE ZHANG
}

Department of Oncology, Shengjing Hospital Affiliated to China Medical University, Shenyang, Liaoning 110000, P.R. China

Received February 27, 2018; Accepted October 3, 2018

DOI: $10.3892 / 01.2019 .9910$

\begin{abstract}
Immune checkpoints expressed on tumor cells may suppress the cytotoxicity of tumor-infiltrating lymphocytes (TILs) via interaction with their ligands. In the present study, checkpoint proteins and ligands, including programmed death-1 (PD-1), programmed death ligand-1 (PD-L1), cluster of differentiation (CD)155 and $\mathrm{T}$ cell immunoreceptor with immunoglobulin and ITIM domains (TIGIT) were systematically analyzed in patients with small cell lung cancer (SCLC). Furthermore their clinicopathological features and survival rates were investigated. Immunohistochemistry was performed in order to analyze the expression of PD-L1, CD155, PD-1 and TIGIT in 60 patients with SCLC, and survival analyses were performed using the Kaplan-Meier method and Cox proportional hazards model. It was reported that CD155/TIGIT and PD-L1/PD-1 were highly expressed on tissues of surgically resected SCLC. High expression levels of PD-L1, CD155 or PD-L1+CD155 were significantly associated with shorter survival. However, high expression levels of PD-1 or TIGIT exhibited no obvious association with shorter survival time. Moreover, patients with SCLC in whom PD-L1 and CD155 levels were highly expressed had the shortest survival rate. Multivariate survival analysis revealed that highly expressed PD-L1 [hazard ratio $(\mathrm{HR})=2.55,95 \%$ confidence interval $(\mathrm{CI})=1.18-5.51, \mathrm{P}=0.017]$ and $\mathrm{CD} 155(\mathrm{HR}=2.40$, 95\% $\mathrm{CI}=1.05-5.50, \mathrm{P}=0.038)$ were independent prognostic factors for overall survival (OS) time in SCLC. In addition, it was reported that TIGIT and PD-1, the receptors of CD155 and PD-L1, respectively, were also constitutively expressed on $\mathrm{CD}^{+}$TILs and tumor cells in SCLC. High expression levels of PD-L1 and CD155 were independent prognostic factors for OS time in patients with SCLC.
\end{abstract}

Correspondence to: Dr Xiaoye Zhang, Department of Oncology, Shengjing Hospital Affiliated to China Medical University, 39 Huaxiang Road, Tiexi, Shenyang, Liaoning 110000, P.R. China E-mail: zhangxy_z4@126.com

Key words: small cell lung cancer, cancer immunotherapy, immune checkpoint, programmed death ligand-1, cluster of differentiation 155

\section{Introduction}

Lung cancer is one of the most common malignant tumors worldwide. Despite the use of multidisciplinary therapies, including surgery, chemotherapy, radiotherapy and gene targeting therapy, the overall survival rate for patients with lung cancer remains poor, particularly for small cell lung cancer (SCLC) (1). Though it only accounts for $15 \%$ of lung cancer cases, SCLC is the most aggressive form of lung cancer, with a 5-year survival rate of only $5 \%$ following diagnosis (2). Despite having increased sensitivity to chemotherapy and radiotherapy, only a small percentage of patients with SCLC attain a complete response (CR), and the majority of patients are likely to experience recurrence. One reason for this is targeted therapies have not yet been developed for SCLC as they have for lung adenocarcinoma, though there have been increasing attempts (3). Therefore, the development of a novel effective therapy is urgently required.

Programmed death-1 (PD-1) is able to directly inhibit the proliferation and cytotoxicity of lymphocytes through interaction with its ligands, programmed death ligand-1 (PD-L1, also termed B7-H1) or PD-L2 (also termed B7-DC) (4). PD-L1 is expressed on tumor tissues and lymphoid organs and is involved in tumor immune suppression, whereas PD-L2 expression is restricted to activated dendritic cells (DCs), macrophages, monocytes and $\mathrm{T}$ cells $(5,6)$. Therefore, PD-L1 was selected in order to study the association between survival time and expression, rather than PD-L2. Blocking the PD-1/PD-1 axis has served an important role in immune therapy for a number of cancer types including melanoma, non-small cell lung cancer (NSCLC), renal cell carcinoma, bladder cancer and hematological malignancies $(7,8)$.

Cluster of differentiation (CD)155, also termed PVR or necl-5, was first discovered during a study about poliovirus infection by Holland et al (9) in 1959. CD155 has been reported to be expressed on numerous tumor cells and activated DCs (10). It has also been reported to serve a number of roles in tumor cells, including cellular adhesion, migration, differentiation, proliferation, survival and metastasis $(11,12)$. Another important function of CD155 is immune regulation (13). The immune-regulatory role and clinical significance of CD155 is complex and not well understood in the tumor microenvironment. It is able to inhibit cell cytotoxicity and the proliferation of lymphocytes via interaction with $\mathrm{T}$ cell immunoreceptor with immunoglobulin 
and ITIM domains (TIGIT), CD96 or CD112R. It is also able to activate lymphocytes by interacting with CD226 (Fig. 1). TIGIT was first described in 2005 by Abbas et al (14). TIGIT, CD96 and CD112R, as co-inhibitors, compete with the co-stimulator CD226 for their ligands (CD155 and CD112) (15). The inhibitory function of TIGIT still serves a dominant role when TIGIT is co-expressed with CD226 and CD96 (16). Notably, the anti-tumor effect was improved with the addition of anti-TIGIT, anti-CD96 or anti-CD112R (17-19). However, there have been fewer studies performed to investigate the immune-regulatory effect of CD155 in the tumor microenvironment, though there are increasing numbers of studies regarding immune checkpoint inhibitors in cancer therapy.

In the present study, the association between the expression levels of immune checkpoint proteins (PD-1/PD-L1 and TIGIT/CD155) and the overall survival (OS) of patients with SCLC was investigated. The expression levels of PD-1/PD-L1 and TIGIT/CD155 in clinical specimens from 60 patients with SCLC were analyzed by immunohistochemistry (IHC). In addition, survival analyses were performed using the Kaplan-Meier method and Cox proportional hazards model. The expression levels of PD-1/TIGIT on CD8 ${ }^{+} \mathrm{T}$ lymphocytes were detected by immunofluorescence.

\section{Patients and methods}

Patients and tissue specimens. The present study was approved by the ethics committee of Shengjing Hospital affiliated to China Medical University (Shenyang, China; no. 2016PS256K), and the need for informed consent from patients was exempted due to the use of retrospective paraffin-embedded specimens. Pathological specimens were collected from 60 patients with SCLC who underwent surgery at Shengjing Hospital affiliated to China Medical University between 2008 and 2014, though five patients were lost to follow-up. The majority (43/60) of these patients with T2-3 or N1-2 (20) metastasis had not been diagnosed correctly due to the lack of effective pathological determination, and unnecessarily underwent surgery as a result of this. The nodules from certain patients with established SCLC were resected, and these patients were in the 1A stage (17/60 T1N0M0 in Tumor-Node-Metastasis staging) with no infiltration in the visceral pleura, main bronchus, surrounding lymph nodes or distant organs, and the tumor size was $<3 \mathrm{~cm}$. Tumor staging was based on serum tumor markers [carcinoembryonic antigen, Cyfra 21-1, neuron specific enolase (NSE) and squamous cell carcinoma antigen] and imaging [positron emission tomography/computed tomography $(\mathrm{PET} / \mathrm{CT})$ or chest $\mathrm{CT}$ scan, bone emission $\mathrm{CT}$ and brain contrast-enhanced magnetic resonance imaging] prior to surgery. Patients who had received neoadjuvant therapy or had an immune system-associated disease were excluded. Histological diagnoses were based on the guidelines of the World Health Organization (21).

NSE is one of the key markers used to evaluate the progression of patients with SCLC (22). Patients with SCLC may also present with hyponatremia, which is caused by inappropriate secretion of antidiuretic hormone or paraneoplastic syndrome. Hyponatremia predicts a poor outcome for patients with SCLC (23). Additionally, a number of patients with SCLC and

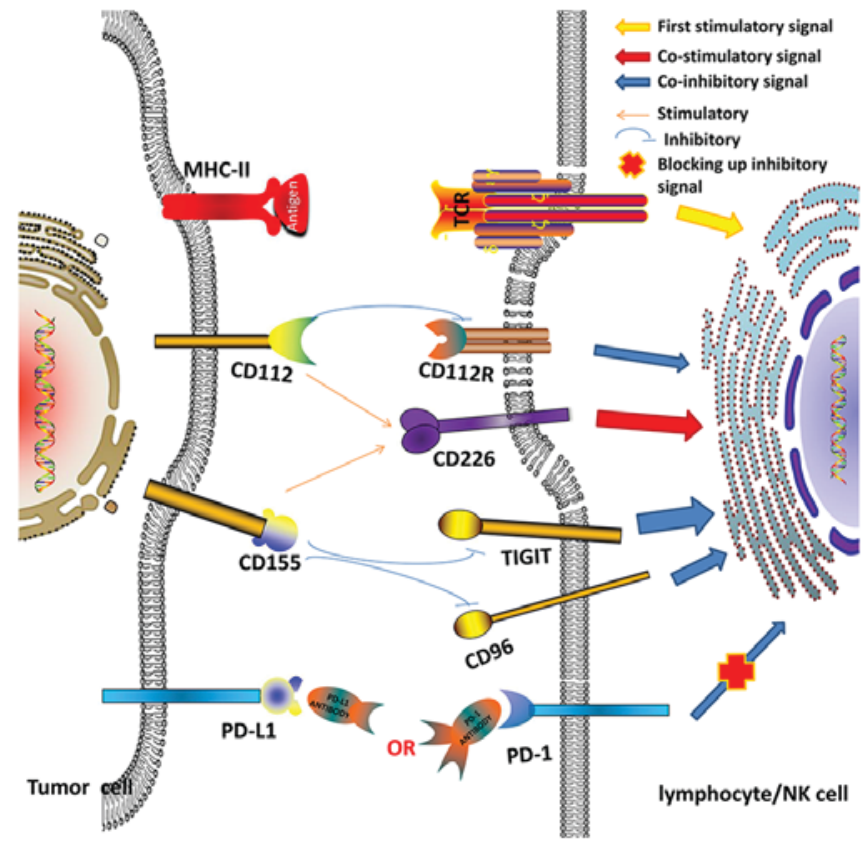

Figure 1. Association between co-stimulatory (CD226) and co-inhibitory (PD-1, TIGIT, CD96 and CD112R) molecules and their ligands (PD-L1,CD112 and $\mathrm{CD} 155)$ in the tumor microenvironment. $\mathrm{CD}$, cluster of differentiation; PD, programmed death; PD-L, programmed death ligand; TIGIT, T cell immunoreceptor with immunoglobulin and ITIM domains; MHC, major histocompatibility complex; NK, natural killer; TCR, T cell receptor.

hypercoagulability (high levels of D-dimer) also have a worse prognosis (24). Serum NSE levels, $\mathrm{Na}^{+}$levels and D-dimer levels were measured 1 day following admission to hospital, at least 1 week prior to surgery. The serum levels of these components were measured using the NSE detection kit (Roche Diagnostics GmbH, Mannheim, Germany), the OLYMPUS $\mathrm{K}^{+}$and AU640/5400/5800 assays (Beckman Coulter, Inc., Brea, CA, USA), and the HemosIL D-dimer HS 500 assay (Instrumentation Laboratory Co., Bedford, MA, USA), according to the manufacturers' protocols. Clinicopathological variables collected for analysis included sex, tumor location, age at diagnosis, tumor size, node involvement (N), NSE expression levels, $\mathrm{Na}^{+}$levels and D-dimer expression levels. Disease recurrence and survival were observed in the follow-up clinic or obtained through telephone correspondence. Follow-up was until mortality or December 2015.

IHC. A total of 60 paraffin-embedded SCLC specimens were obtained from the Pathology Department of the Shengjing Hospital affiliated to China Medical University. The samples had been fixed in $10 \%$ formalin for $2 \mathrm{~h}$ at room temperature. IHC was performed on the resected SCLC tumor tissues ( $3 \mu \mathrm{m}$ thickness) using primary antibodies: Anti-TIGIT antibody (1:50 dilution; cat. no. sc-103319), anti-CD155 antibody (1:100 dilution; cat. no. sc-514623; both Santa Cruz Biotechnology, Inc., Dallas, TX, USA), anti-PD-1 antibody (1:100 dilution; cat. no. 66220-1-Ig) and anti-PD-L1 antibody (1:200 dilution; cat. no. 66248-1-Ig) (both ProteinTech Group, Inc., Chicago, IL, USA), and IHC kits containing horseradish peroxidase-conjugated affinipure rabbit anti-goat/goat anti-rabbit/goat anti-mouse secondary antibodies (cat. nos. ZB-2306, ZB-2301 and ZB-2305, respectively; dilutions as supplied; OriGene Technologies, Inc., Beijing, China) 


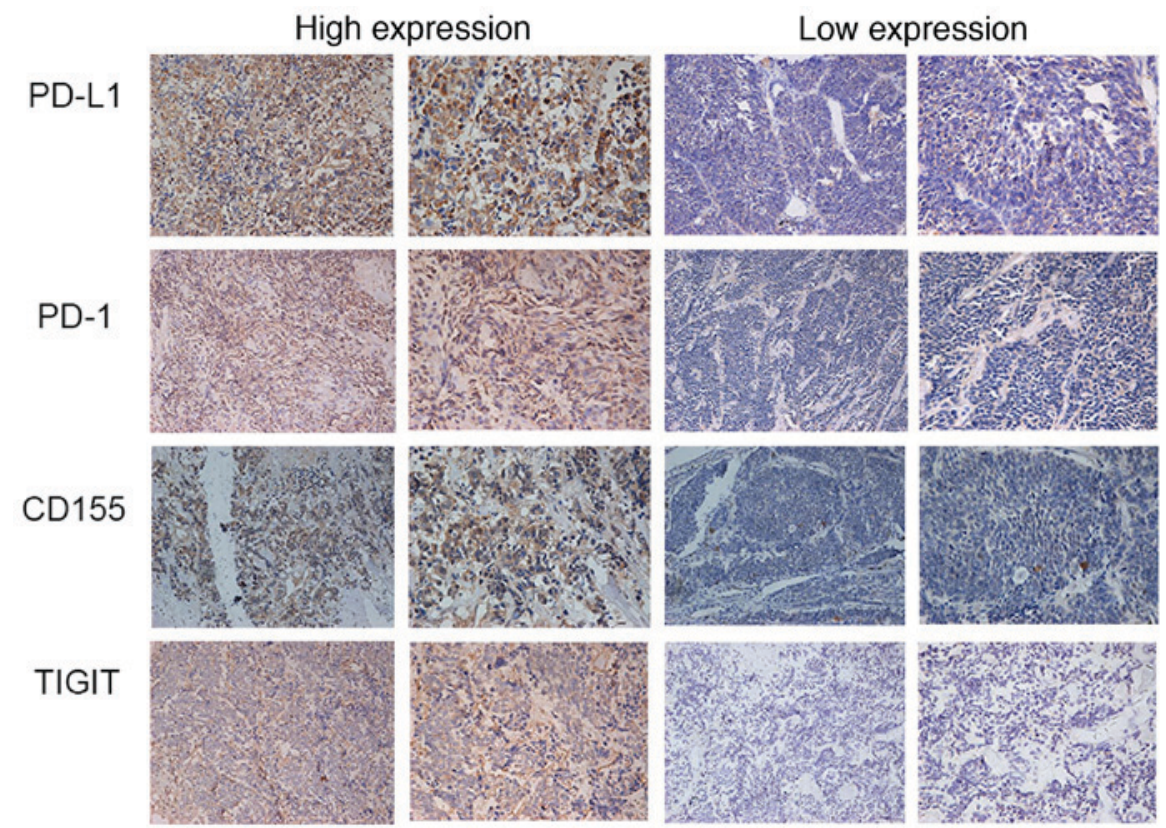

Figure 2. Expression of PD-L1, PD-1, CD155 and TIGIT in SCLC detected by immunohistochemistry (left panels, magnification, x200; right panels, magnification, $\mathrm{x} 400$ ). CD, cluster of differentiation; PD, programmed death; PD-L, programmed death ligand; TIGIT, T cell immunoreceptor with immunoglobulin and ITIM domains.

according to the manufacturer's protocols. The specimens were deparaffinized in $100 \%$ xylene for $15 \mathrm{~min}$ at room temperature, rehydrated in descending ethanol series for $5 \mathrm{~min}$ at room temperature, and incubated in $3 \% \mathrm{H}_{2} \mathrm{O}_{2}$ for $1 \mathrm{~h}$ at room temperature. Antigen retrieval was achieved by heating the samples in citrate buffer ( $\mathrm{pH} 6.0$ ) for $10 \mathrm{~min}$ at $95^{\circ} \mathrm{C}$. The specimens were incubated with the protein blocking solution provided by the IHC kits for $1-2 \mathrm{~h}$ at room temperature, then incubated with the primary antibodies in a humid chamber overnight at $4^{\circ} \mathrm{C}$. The negative controls were treated with PBS instead of the primary antibodies. Following incubation with the secondary antibodies for $1 \mathrm{~h}$ at room temperature, the specimens were stained using a DAB kit (OriGene Technologies, Inc.). All sections were counterstained with $100 \%$ hematoxylin for $30 \mathrm{sec}$ at room temperature. All images were recorded using a Nikon E800 fluorescent microscope and analyzed with NIS-Elements $\mathrm{Br}$ version 4.60.00 (Nikon Corporation, Tokyo, Japan). All IHC results were assessed by two pathologists independently in a blinded manner. Discordant opinions were settled by a third pathologist. The intensity of staining was defined as follows: No staining was considered a negative result (' 0 '); positively stained sections were analyzed using the integrated optical density (IOD) and the areas of staining distribution with NIS-Elements $\mathrm{Br}$ version 4.60.00; the mean density was obtained by dividing the IOD value by the area, and an average from 5 representative fields was calculated (magnification, $\mathrm{x} 400$ ).

Immunofluorescence. The deparaffinization and antigen retrieval of the sections was carried out as described for the IHC method. Nonspecific immunoglobulin binding was blocked using $5 \%$ bovine serum albumin (cat. no. 8850; Beijing Solarbio Science \& Technology Co., Ltd., Beijing, China) for $2 \mathrm{~h}$ at room temperature. Sections were incubated with primary anti-TIGIT antibody and anti-CD8 antibody (1:75 dilution; cat. no. 17335-1-AP; ProteinTech Group, Inc.), or with
anti-PD-1 antibody and anti-CD8 antibody (1:75 dilution; cat. no. 17335-1-AP; ProteinTech Group, Inc.) at $4^{\circ} \mathrm{C}$. Following overnight incubation, the slides were incubated for $4 \mathrm{~h}$ at room temperature with the following mixed fluorescent secondary antibodies: i) Tetramethylrhodamine (TRITC)-goat anti-rabbit secondary antibody (1:50 dilution; cat. no. ZF-0316); ii) fluorescein isothiocyanate (FITC)-goat anti-mouse second antibody (1:100 dilution; cat. no. ZF-0312; both OriGene Technologies, Inc.); iii) TRITC-donkey anti-goat secondary antibody (1:50 dilution; cat. no. sc-2094); and iv) FITC-donkey anti-rabbit secondary antibody (1:100 dilution; cat. no. sc-2090; both Santa Cruz Biotechnology, Inc.), followed by incubation with DAPI (Beijing Solarbio Science \& Technology Co., Ltd.) for $5 \mathrm{~min}$ at room temperature. Finally, the images were observed and captured (x400 magnification) using a fluorescence microscope (Eclipse NI; Nikon Corporation).

Statistical analysis. The association between the marker expression levels and the clinicopathological features was analyzed using a Pearson's $\chi^{2}$ test. The survival analysis for different groups was performed using a Kaplan-Meier survival (log-rank tests). The Cox regression model was used to perform multivariate analysis. The statistical results were performed using SPSS software, version 20.0 (IBM Corp., Armonk, NY, USA). $\mathrm{P}<0.05$ was considered to indicate a statistically significant difference.

\section{Results}

Association between PD-1,PD-L1,TIGIT and CD155 expression levels and clinicopathological features. PD-1,PD-L1, TIGIT and CD155 expression levels were analyzed in 60 human SCLC tissues by IHC. PD-1/PD-L1 and TIGIT/CD155 were highly expressed, particularly in the cytoplasm and cell membrane of cancer cells and the matrix of tumor tissue (Fig. 2). The mean densities of 
Table I. Association between PD-L1/CD155 expression and patient characteristics in 60 patients with small cell lung cancer.

\begin{tabular}{|c|c|c|c|c|c|c|}
\hline \multirow[b]{2}{*}{ Characteristic } & \multicolumn{3}{|c|}{ PD-L1 expression } & \multicolumn{3}{|c|}{ CD155 expression } \\
\hline & Low, $\mathrm{n}$ & High, $n$ & P-value & Low, $\mathrm{n}$ & High, $n$ & P-value \\
\hline Sex & & & 0.382 & & & 0.901 \\
\hline Male & 15 & 28 & & 21 & 22 & \\
\hline Female & 8 & 9 & & 8 & 9 & \\
\hline Location of tumor & & & 0.914 & & & 0.399 \\
\hline Left lung & 9 & 15 & & 10 & 14 & \\
\hline Right lung & 14 & 22 & & 19 & 17 & \\
\hline Age at diagnosis, years & & & 0.986 & & & 0.768 \\
\hline$\leq 60$ & 13 & 21 & & 17 & 17 & \\
\hline$>60$ & 10 & 16 & & 12 & 14 & \\
\hline Tumor size, cm & & & 0.009 & & & 0.553 \\
\hline$\leq 3$ & 19 & 18 & & 19 & 18 & \\
\hline$>3$ & 4 & 19 & & 10 & 13 & \\
\hline $\mathrm{N}$ status & & & 0.317 & & & 0.835 \\
\hline N0 & 10 & 10 & & 10 & 10 & \\
\hline N1 & 6 & 9 & & 8 & 7 & \\
\hline $\mathrm{N} 2$ & 7 & 18 & & 11 & 14 & \\
\hline Preoperative serum NSE level (ng/ml) & & & 0.007 & & & 0.021 \\
\hline Normal (0-16.3) & 15 & 11 & & 17 & 9 & \\
\hline Elevated $(>16.3)$ & 8 & 26 & & 12 & 22 & \\
\hline Preoperative serum $\mathrm{Na}^{+}$level (mM) & & & 0.103 & & & 0.945 \\
\hline Normal (136-145) & 23 & 33 & & 27 & 29 & \\
\hline Reduced $(<136)$ & 0 & 4 & & 2 & 2 & \\
\hline Preoperative serum D-dimer level $(\mu \mathrm{g} / \mathrm{l})$ & & & 0.690 & & & 0.245 \\
\hline Normal (0-252) & 19 & 29 & & 25 & 23 & \\
\hline Elevated (>252) & 4 & 8 & & 4 & 8 & \\
\hline
\end{tabular}

CD, cluster of differentiation; PD-L, programmed death ligand; NSE, neuron specific enolase; N, node.

PD-1, PD-L1, TIGIT and CD155 staining in the 60 SCLC samples from patients were $0.288,0.316,0.302$ and 0.304 , respectively (data not shown). Detailed clinicopathological characteristics are presented in Table I. It was reported that high expression levels PD-L1 and CD155 in tumors were associated with high levels of NSE expression (PD-L1, $\mathrm{P}=0.007$; CD155, $\mathrm{P}=0.021$ ), and larger tumor size was associated with high expression levels of PD-L1 ( $\mathrm{P}=0.009)$. Therefore, it was hypothesized that NSE may be a useful factor when selecting patients with SCLC who may benefit from checkpoint (anti-PD-L1 or anti-CD155) targeting therapy. There was no significant association between high PD-L1 or CD155 expression levels and $\mathrm{N}, \mathrm{Na}^{+}$or D-dimer expression levels.

Expression levels and prognostic value of PD-1/PD-L1 and TIGIT/CD155 in human SCLC. Patients were divided into two groups according to the median PD-L1 or CD155 expression levels; these groups were a PD-L1 high/low group and a CD155 high/low group, respectively. As presented in Fig. 3, patients with higher PD-L1 or CD155 expression levels tended to have shorter OS times (PD-L1, 16.26 \pm 2.91 months; CD155, $16.20 \pm 2.42$ months) compared with patients in the low expression group (PD-L1, 36.43 \pm 6.46 months; CD155, 29.87 \pm 3.66 months) (PD-L1, $\mathrm{P}=0.001$; CD155, $\mathrm{P}=0.002)$. However, in the PD-1 and TIGIT high and low expression groups, there were no significant associations with survival time.

Patients were subsequently divided into three groups: i) PD-L1 and CD155 low expression levels $(n=14)$; ii) either PD-L1 or CD155 overexpression $(n=22)$; or iii) PD-L1 and CD155 overexpression $(n=24)$. Significant differences in OS were reported between groups $(\mathrm{P}<0.001$ for $\mathrm{OS}$, as presented in Fig. 3). The OS of patients with PD-L1 or CD155 overexpression alone (26.70 \pm 6.99 months) tended to be shorter compared with patients with low expression of the two (38.82 \pm 2.67 months), and the OS of patients who had high expression levels of PD-L1 and CD155 together was the poorest $(13.13 \pm 2.53$ months $)(\mathrm{P}<0.001)$.

To determine the prognostic value of the expression levels of these immune checkpoints, Kaplan-Meier survival calculations (log-rank tests) were used for sex, tumor 

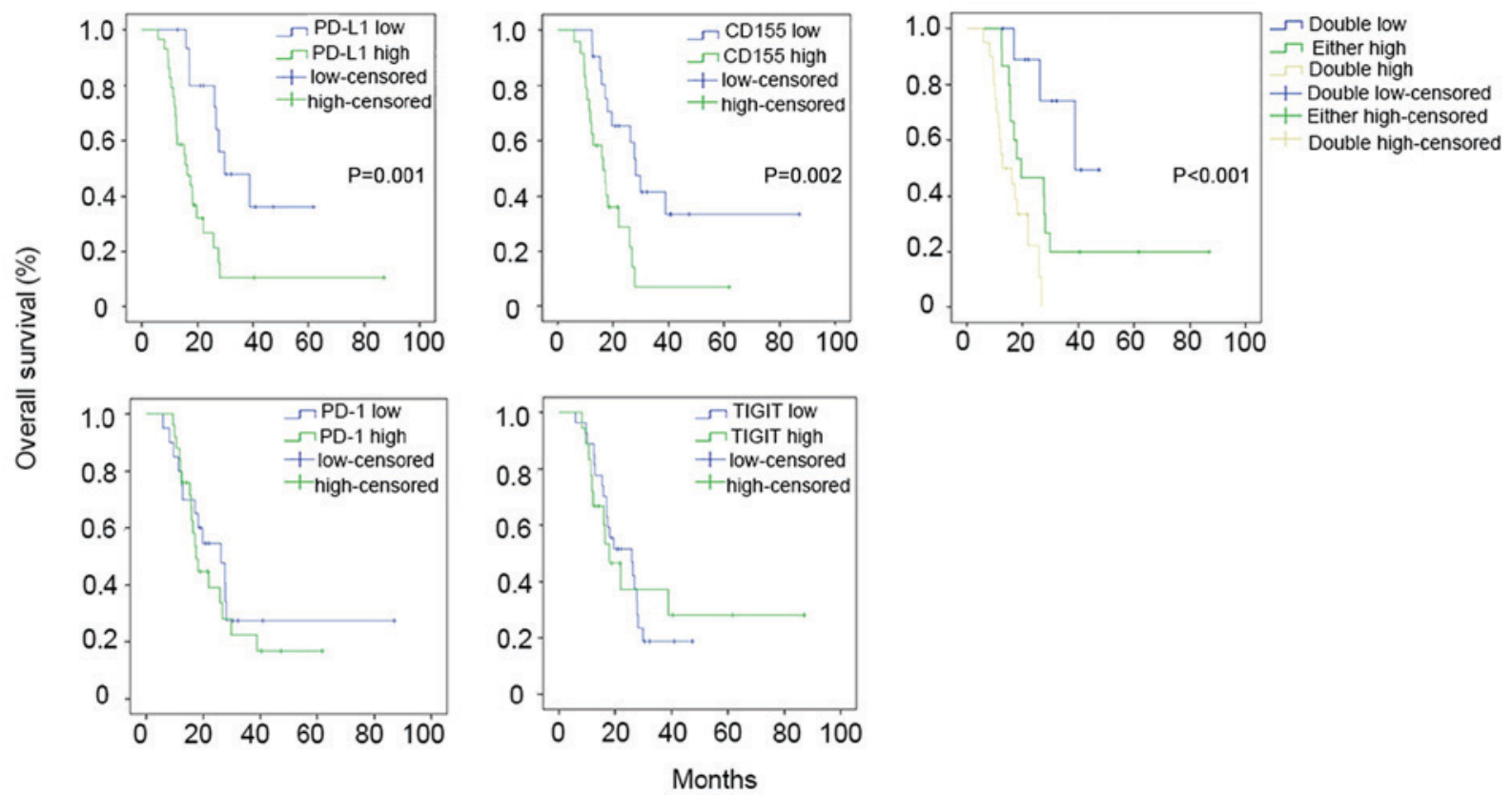

Figure 3. Kaplan-Meier curves comparing OS rates between the high and low expression groups of PD-L1, PD-1, CD155 and TIGIT. SCLC patients with higher PD-L1 expression (PD-L1-high group) tended to have a shorter OS (16.26 \pm 2.91 months) compared with the PD-L1-low group (36.43 \pm 6.46 months; $\mathrm{P}=0.001)$. SCLC patients with higher CD155 expression (CD155-high group) tended to have a shorter OS (16.20 \pm 2.42 months) compared with the CD155-low group (29.87 \pm 3.66 months; $\mathrm{P}=0.002$ ). Furthermore, patients were divided into three groups based on the expression levels of CD155 and PD-L1. The OS of SCLC patients with PD-L1 or CD155 overexpression (26.70 \pm .99 months) tended to be shorter compared with patients with low expression levels of both (38.82 \pm 2.67 months), and the OS of patients who had high expression levels of PD-L1 and CD155 was poorest (13.13 \pm 2.53 months) (P<0.001). In the PD-1 and TIGIT high or low expression groups, there were no significant associations with survival time. Low or high-censored indicates censored data in the low/high expression groups. These censored data represent patients with SCLC who were lost to follow-up or still alive at the end of the follow-up time. $\mathrm{CD}$, cluster of differentiation; PD, programmed death; PD-L, programmed death ligand; TIGIT, T cell immunoreceptor with immunoglobulin and ITIM domains; SCLC, small cell lung cancer; OS, overall survival.

location, age at diagnosis, tumor size, $\mathrm{N}$ status, PD-L1, CD155, PD-1, TIGIT, NSE, $\mathrm{Na}^{+}$, D-dimer and postoperative therapeutic methods. It was reported that PD-L1 $(\mathrm{P}=0.001)$, CD155 ( $\mathrm{P}=0.002), \mathrm{N}$ status $(\mathrm{P}=0.046), \mathrm{NSE}(\mathrm{P}=0.047)$ and postoperative therapeutic methods $(\mathrm{P}=0.004)$ were associated with the OS of patients with SCLC (Table II). Furthermore, a multivariate Cox regression model was used to analyze PD-L1, CD155, N status, NSE and postoperative therapeutic methods to determine their prognostic value. High expression levels of PD-L1 [hazard ratio $(\mathrm{HR})=2.55,95 \%$ confidence interval $(\mathrm{CI})=1.18-5.51, \mathrm{P}=0.017]$ and $\mathrm{CD} 155(\mathrm{HR}=2.40$, 95\% $\mathrm{CI}=1.05-5.50, \mathrm{P}=0.038$ ) were independent predictors of poor OS in patients with SCLC (Table III).

$P D-1$, and TIGIT expression levels on $C D 8^{+}$tumor-infiltrating lymphocytes (TILs). Using immunofluorescence double staining, it was demonstrated that PD-1 and TIGIT were expressed on $\mathrm{CD}^{+}$TILs in certain specimens from SCLC patients (Fig. 4). These results confirmed that in SCLC, the receptors of CD155 and PD-L1, TIGIT and PD-1, were constitutively expressed on $\mathrm{CD} 8^{+}$TILs. It is possible that PD $-1^{+}$ or TIGIT $^{+} \mathrm{CD}^{+}$TILs are involved in immune regulation by interacting with ligands expressed on tumor cells.

\section{Discussion}

Increasing attention has been focused on tumor immunotherapy, which primarily includes blocking immune checkpoints, designing genetic modifications in patient lymphocytes targeted to tumor-specific antigens and tumor-associated antigens prior to infusion (25), or vaccines that improve the immunogenicity of tumor antigens (26). As pioneering immune checkpoint blockers, anti-CTLA-4 (Ipilimumab), anti-PD-1s (Nivolumab and Pembrolizumab) and anti-PD-L1s (Durvalumab and Atezolizumab) have already been applied in the therapy of a number of solid cancer types, including melanoma (27) and non-small cell lung cancer (28), and these immune checkpoint inhibitors display marked clinical efficacy, particularly in patients with overexpression of checkpoint proteins (29). Thus, it is vitally important to assess the expression levels of checkpoint proteins in SCLC prior to further immune therapy.

The present study investigated the expression levels of PD-1/PD-L1 and TIGIT/CD155 in SCLC. As in NSCLC, melanoma, renal cell carcinoma and pancreatic cancer (30), high expression levels of PD-L1 in SCLC were demonstrated to be an independent risk factor for an unfavorable outcome. In addition, a multivariate survival analysis revealed that a high expression level of CD155 was also an independent risk factor for an unfavorable outcome in patients with SCLC. Certain studies have reported that CD155 is overexpressed in lung adenocarcinoma (31), soft tissue sarcoma (32) and pancreatic cancer (33), and that survival times in patients with CD155 overexpression are significantly shorter compared with patients with low CD155 expression. Another study on hepatocellular carcinoma (HCC) reported that CD155 expression was lower compared with adjacent tissue, and patients with highly expressed CD155 were significantly more likely to have a good prognosis (34). This may partly be due to the 
Table II. Univariate prognostic analysis of 60 patients with small cell lung cancer.

\begin{tabular}{|c|c|c|c|}
\hline Characteristic & Patients, $\mathrm{n}$ & OS time, months & P-value \\
\hline Sex & & & 0.741 \\
\hline Male & 41 & 22.13 & \\
\hline Female & 14 & 18.03 & \\
\hline Location of tumor & & & 0.494 \\
\hline Left lung & 24 & 18.13 & \\
\hline Right lung & 31 & 26.70 & \\
\hline Age at diagnosis, years & & & 0.091 \\
\hline$\leq 60$ & 31 & 26.70 & \\
\hline$>60$ & 24 & 17.02 & \\
\hline Tumor size, $\mathrm{cm}$ & & & 0.328 \\
\hline$\leq 3$ & 34 & 25.93 & \\
\hline$>3$ & 21 & 18.03 & \\
\hline $\mathrm{N}$ status & & & 0.046 \\
\hline No & 18 & 26.3 & \\
\hline N1 & 15 & 25.9 & \\
\hline $\mathrm{N} 2$ & 22 & 17.4 & \\
\hline PD-L1 expression & & & 0.001 \\
\hline Low & 21 & 36.43 & \\
\hline High & 34 & 16.26 & \\
\hline CD155 expression & & & 0.002 \\
\hline Low & 26 & 29.87 & \\
\hline High & 29 & 16.20 & \\
\hline PD-1 expression & & & 0.781 \\
\hline Low & 25 & 22.13 & \\
\hline High & 30 & 22.03 & \\
\hline TIGIT expression & & & 0.874 \\
\hline Low & 34 & 25.93 & \\
\hline High & 21 & 18.03 & \\
\hline Preoperative serum NSE level & & & 0.047 \\
\hline Normal & 24 & 27.80 & \\
\hline Elevated & 31 & 18.03 & \\
\hline Preoperative serum $\mathrm{Na}^{+}$level & & & 0.857 \\
\hline Normal & 52 & 22.03 & \\
\hline Reduced & 3 & 22.67 & \\
\hline Preoperative serum D-dimer level & & & 0.684 \\
\hline Normal & 45 & 25.93 & \\
\hline Elevated & 10 & 17.02 & \\
\hline Postoperative therapy & & & 0.004 \\
\hline No therapy & 9 & 17.02 & \\
\hline Chemotherapy & 16 & 18.13 & \\
\hline Chemotherapy and radiotherapy & 30 & 28.13 & \\
\hline
\end{tabular}

$\mathrm{CD}$, cluster of differentiation; PD, programmed death; PD-L, programmed death ligand; NSE, neuron specific enolase; TIGIT, T cell immunoreceptor with immunoglobulin and ITIM domains. 
Table III. Multivariate Cox regression analysis of overall survival in 60 patients with small cell lung cancer.

\begin{tabular}{lcr}
\hline Factor & HR $(95 \% \mathrm{CI})$ & P-value \\
\hline PD-L1 expression (high vs. low) & $2.55(1.18-5.51)$ & 0.017 \\
CD155 expression (high vs. low) & $2.40(1.05-5.50)$ & 0.038 \\
NSE (elevated vs. normal) & $1.76(0.88-3.53)$ & 0.113 \\
N status (N2/N1/N0) & $1.45(0.94-2.23)$ & 0.092 \\
Therapy (chemotherapy and radiotherapy vs. & $0.76(0.46-1.25)$ & 0.278 \\
chemotherapy vs. surgery) & &
\end{tabular}

HR, hazard ratio; CI, confidence interval; CD, cluster of differentiation; PD-L, programmed death ligand; NSE, neuron specific enolase.
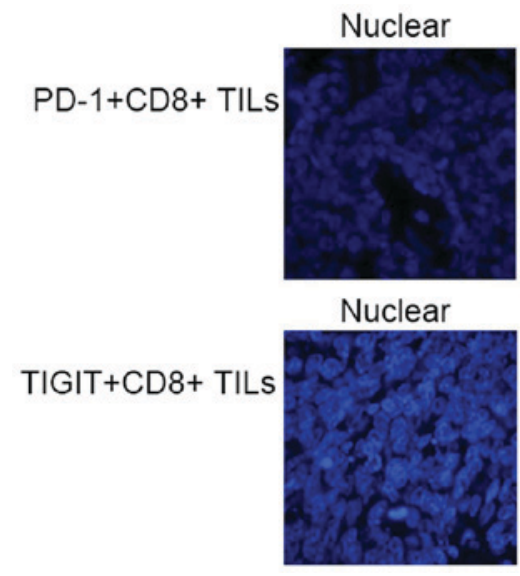

$\mathrm{CD} 8$

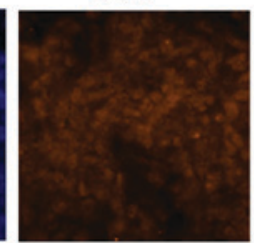

TIGIT

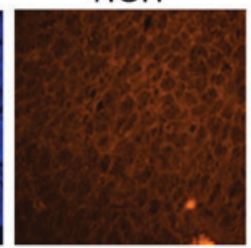

PD-1

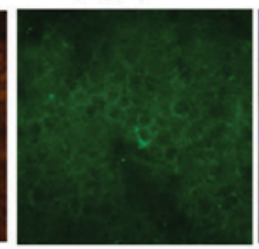

$\mathrm{CD} 8$

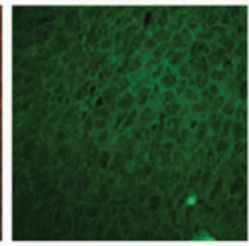

Merged

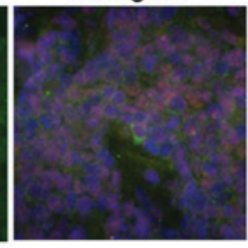

Merged

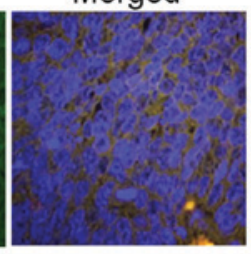

Figure 4. Immunofluorescence double staining of PD-1/TIGIT and CD8 in small cell lung cancer. Nuclear staining with DAPI (blue); CD8 staining with TRITC-goat anti-rabbit second antibody (red) or FITC-donkey anti-rabbit second antibody (green); PD-1 staining with FITC-goat anti-mouse second antibody (green); TIGIT staining with TRITC-donkey anti-goat second antibody (red). Sections were photographed at magnification, x400. CD, cluster of differentiation; PD, programmed death; TIGIT, T cell immunoreceptor with immunoglobulin and ITIM domains; FITC, fluorescein isothiocyanate; TRITC, tetramethylrhodamine; TILs, tumor-infiltrating lymphocytes.

may serve a more important role compared with CD155/TIGIT in HCC, or CD155/TIGIT may safeguard liver regeneration by regulating NK cell-hepatocyte crosstalk (35). SCLC, however, is a classical neuroendocrine tumor, and its immune regulation is more complex compared with other types of solid tumors due to the existence of autocrine or paracrine molecules, including NSE. Consequently, it is useful to understand the prognostic value of CD155 in SCLC. Furthermore, CD155 has four isoforms created by alternative splicing: $\alpha, \beta, \gamma$ and $\delta ; C D 155 \alpha$ and CD155 $\delta$ are transcribed into membrane proteins, while CD155 $\beta$ and CD155 $\gamma$ are transcribed into serum proteins $(36,37)$. The secreted CD155 (sCD155) isoform was reported to be expressed in the liver, serum and other human tissues, and it may compete with membrane CD155 in poliovirus entry and immune regulation (36). Recently, it was hypothesized that sCD155 in serum may be a biomarker to predict cancer development and progression (38). The prognostic value of CD155 in SCLC requires further investigation.

Finally, it was demonstrated that TIGIT/PD-1 was expressed on $\mathrm{CD}^{+}$TILs, which suggested that tumor cells may upregulate PD-L1 and CD155 during immune evasion, by interacting with their ligands expressed on lymphocytes to suppress their cytotoxic functions. The association between co-stimulatory molecules, co-inhibitory molecules and their ligands is complex and not well defined. On the one hand,
CD155 and CD112 (nectin-2) expressed on antigen presenting cells are able to interact with co-inhibitory molecules, including TIGIT, CD96 and CD112R, which are expressed on immunocytes to weaken their immune function; on the other hand, CD155 is also able to react with its co-stimulatory molecule, CD226 (DNAM-1), to activate immunocytes and strengthen immunological surveillance $(18,19,39-41)$. The competition between them leads to immune invasion. However, the present study was a retrospective analysis, therefore there are limitations. It is not possible to use retrospective postoperative paraffin-embedded sections for the efficient extraction of protein or RNA required for subsequent western blotting or reverse transcription-quantitative polymerase chain reaction. Therefore, further investigations are required.

In conclusion, the present results indicated that high expression levels of PD-L1 and CD155 were independent indicators of a decreased OS in patients with SCLC. In addition, patients with SCLC and high expression levels of CD155 and PD-L1 displayed the shortest survival times.

\section{Acknowledgements}

The authors would like to thank the Pathology Department of Shengjing Hospital affiliated to China Medical University for the acquisition of human tumor specimens. 


\section{Funding}

The present study was funded by the Department of Science and Technology of Liaoning Province, Liaoning Province Finance Department (grant no. 2014021032).

\section{Availability of data and materials}

The datasets generated and/or analyzed during this study are available from the corresponding author on reasonable request.

\section{Authors' contributions}

$\mathrm{XZ}$ and $\mathrm{YX}$ conceived and designed the experiments and performed the experiments; YX and ZJ analyzed the data; YX, GC, ZJ and NL collected clinical data and samples; YX and $\mathrm{XZ}$ contributed reagents/materials/analysis tools; and YX and $\mathrm{XZ}$ wrote the manuscript. All authors read and approved the final manuscript.

\section{Ethics approval and consent to participate}

All procedures performed in studies involving human participants were in accordance with the ethical standards of the institutional and/or national research committee and with the 1964 Helsinki declaration and its later amendments, or comparable ethical standards. Informed consent was waived due to the use of retrospective specimens in the study. The present study was approved by the Shengjing Hospital affiliated to China Medical University ethics committee (no. 2016PS256K).

\section{Patient consent for publication}

This study was approved by the ethics committee of Shengjing Hospital affiliated to China Medical University (no. 2016PS256K), and the need for informed consent from patients was exempted due to the use of retrospective and abandoned paraffin-embedded specimens.

\section{Competing interests}

The authors declare that they have no competing interests.

\section{References}

1. Siegel RL, Miller KD and Jemal A: Cancer statistics, 2016. CA Cancer J Clin 66: 7-30, 2016.

2. Torre LA, Bray F, Siegel RL, Ferlay J, Lortet-Tieulent J and Jemal A, Global cancer statistics, 2012. CA Cancer J Clin 65: 87-108, 2015

3. Fiorentino FP, Tokgün E, Solé-Sánchez S, Giampaolo S, Tokgün O, Jauset T, Kohno T, Perucho M, Soucek L and Yokota J: Growth suppression by MYC inhibition in small cell lung cancer cells with TP53 and RB1 inactivation. oncotarget 7: 31014-31028, 2016.

4. Keir ME, Butte MJ, Freeman GJ and Sharpe AH: PD-1 and its ligands in tolerance and immunity. Annu Rev Immunol 26: 677-704, 2008.

5. Yamazaki T, Akiba H, Iwai H, Matsuda H, Aoki M, Tanno Y, Shin T, Tsuchiya H, Pardoll DM, Okumura K, et al: Expression of programmed death 1 ligands by murine T cells and APC. J Immunol 169: 5538-5545, 2002.

6. Chinai JM, Janakiram M, Chen F, Chen W, Kaplan M and Zang X: New immunotherapies targeting the PD-1 pathway. Trends Pharmacol Sci 36: 587-595, 2015.
7. Brahmer JR, Tykodi SS, Chow LQ, Hwu WJ, Topalian SL, Hwu P, Drake CG, Camacho LH, Kauh J, Odunsi K, et al: Safety and activity of anti-PD-L1 antibody in patients with advanced cancer. N Engl J Med 366: 2455-2465, 2012.

8. Topalian SL, Hodi FS, Brahmer JR, Gettinger SN, Smith DC, McDermott DF, Powderly JD, Carvajal RD, Sosman JA, Atkins MB, et al: Safety, activity, and immune correlates of anti-PD-1 antibody in cancer. N Engl J Med 366: 2443-2454, 2012.

9. Holland JJ, McLaren LC and Syverton JT: Mammalian cell-virus relationship. III. Poliovirus production by non-primate cells exposed to poliovirus ribonucleic acid. Proc Soc Exp Biol Med 100: 843-845. 1959.

10. Pende D, Castriconi R, Romagnani P, Spaggiari GM, Marcenaro S, Dondero A, Lazzeri E, Lasagni L, Martini S, Rivera P, et al: Expression of the DNAM-1 ligands, nectin-2 (CD112) and poliovirus receptor (CD155), on dendritic cells: Relevance for natural killer-dendritic cell interaction. Blood 107: 2030-2036, 2006.

11. Rikitake Y, Mandai $\mathrm{K}$ and Takai $\mathrm{Y}$ : The role of nectins in different types of cell-cell adhesion. J Cell Sci 125: 3713-3722, 2012.

12. Sloan KE, Eustace BK, Stewart JK, Zehetmeier C, Torella C, Simeone M, Roy JE, Unger C, Louis DN, Ilag LL and Jay DG: CD155/PVR plays a key role in cell motility during tumor cell invasion and migration. BMC Cancer 4: 73, 2004.

13. Kamran N, Takai Y, Miyoshi J, Biswas SK, Wong JS and Gasser S: Toll-like receptor ligands induce expression of the costimulatory molecule CD155 on antigen-presenting cells. PLoS One 8: e54406, 2013.

14. Abbas AR, Baldwin D, Ma Y, Ouyang W, Gurney A, Martin F, Fong S, van Lookeren Campagne M, Godowski P, Williams PM, et al: Immune response in silico (IRIS): Immune-specific genes identified from a compendium of microarray expression data. Genes Immun 6: 319-331, 2005.

15. Li M, Xia P, Du Y, Liu S, Huang G, Chen J, Zhang H, Hou N, Cheng X,Zhou L, et al: T-cell immunoglobulin and ITIM domain (TIGIT) receptor/poliovirus receptor (PVR) ligand engagement suppresses interferon- $\gamma$ production of natural killer cells via $\beta$-arrestin 2-mediated negative signaling. J Biol Chem 289: 17647-17657, 2014.

16. Stanietsky N and Mandelboim O: Paired NK cell receptors controlling NK cytotoxicity. FEBS Lett 584: 4895-4900, 2010.

17. Johnston RJ, Comps-Agrar L, Hackney J, Yu X, Huseni M, Yang Y, Park S, Javinal V, Chiu H, Irving B, et al: The immunoreceptor TIGIT regulates antitumor and antiviral CD8(+) T cell effector function. Cancer Cell 26: 923-937, 2014.

18. Blake SJ, Stannard K, Liu J, Allen S, Yong MC, Mittal D, Aguilera AR, Miles JJ, Lutzky VP, de Andrade LF, et al: Suppression of metastases using a new lymphocyte checkpoint target for cancer immunotherapy. Cancer Discov 6: 446-459, 2016.

19. Zhu Y, Paniccia A, Schulick AC, Chen W, Koenig MR, Byers JT, Yao S, Bevers S and Edil BH: Identification of CD112R as a novel checkpoint for human T cells. J Exp Med 213: 167-176, 2016.

20. Vallières E, Shepherd FA, Crowley J, Van Houtte P, Postmus PE, Carney D, Chansky K, Shaikh Z, Goldstraw P and International Association for the Study of Lung Cancer International Staging Committee and Participating Institutions: The IASLC lung cancer staging project proposals regarding the relevance of TNM in the pathologic staging of small cell lung cancer in the forthcoming (Seventh) edition of the TNM classification for lung cancer. J Thorac Oncol 4: 1049-1059, 2009.

21. Marx A, Chan JK, Coindre JM, Detterbeck F, Girard N, Harris NL, Jaffe ES, Kurrer MO, Marom EM, Moreira AL, et al: The 2015 World Health Organization classification of tumors of the Thymus: Continuity and changes. J Thorac Oncol 10: 1383-1395, 2015.

22. Jørgensen LG, Osterlind K, Genollá J, Gomm SA, Hernández JR, Johnson PW, Løber J, Splinter TA and Szturmowicz M: Serum neuron-specific enolase (S-NSE) and the prognosis in small-cell lung cancer (SCLC): A combined multivariable analysis on data from nine centres. Br J Cancer 74: 463-467, 1996.

23. Wang X, Liu M, Zhang L and Ma K: Syndrome of inappropriate antidiuretic hormone secretion: A poor prognosis in small-cell lung cancer. Arch Med Res 47: 19-24, 2016. 
24. Chen Y, Yu H, Wu C, Li J, Jiao S, Hu Y, Tao H, Wu B and Li A Prognostic value of plasma D-dimer levels in patients with small-cell lung cancer. Biomed Pharmacother 81: 210-217.25, 2016.

25. Kershaw MH, Westwood JA, Slaney CY and Darcy PK: Clinical application of genetically modified T cells in cancer therapy. Clin Transl Immunology 3: e16, 2014.

26. Thomas S and Prendergast GC: Cancer vaccines: A brief overview. Methods Mol Biol 1403: 755-761, 2016.

27. M.J.A.T. Daniel G. Coit, William E. Carson III, Brian Gastman, Julie R. Lange, Rene Gonzalez, Aparna Priyanath Gupta, et al: NCCN guidelines ${ }^{\circledR}$ insights melanoma, version 3.2016 featured updates to the NCCN guidelines. J Natl Compr Cancer Netw 14: 14, 2016.

28. Ettinger DS, Wood DE, Akerley W, Bazhenova LA, Borghaei H, Camidge DR, Cheney RT, Chirieac LR, D'Amico TA, Dilling TJ, et al: NCCN guidelines ${ }^{\circledR}$ insights: Non-small cell lung cancer, version 4.2016 featured updates to the NCCN guidelines. J Natl Compr Canc Netw 14: 255-264, 2016.

29. Schumacher TN, Kesmir C and van Buuren MM: Biomarkers in cancer immunotherapy. Cancer Cell 27: 12-14, 2015.

30. Nomi T, Sho M, Akahori T, Hamada K, Kubo A, Kanehiro H, Nakamura S, Enomoto K, Yagita H, Azuma M and Nakajima Y: Clinical significance and therapeutic potential of the programmed death-1 ligand/programmed death-1 pathway in human pancreatic cancer. Clin Cancer Res 13: 2151-2157, 2007

31. Nakai R, Maniwa Y, Tanaka Y, Nishio W, Yoshimura M, Okita Y, Ohbayashi C, Satoh N, Ogita H, Takai Y and Hayashi Y: Overexpression of Necl-5 correlates with unfavorable prognosis in patients with lung adenocarcinoma. Cancer Sci 101: 1326-1330, 2010.

32. Atsumi S, Matsumine A, Toyoda H, Niimi R, Iino T and Sudo A Prognostic significance of CD155 mRNA expression in soft tissue sarcomas. Oncol Lett 5: 1771-1776, 2013.

33. Nishiwada S, Sho M, Yasuda S, Shimada K, Yamato I, Akahori T, Kinoshita S, Nagai M, Konishi N and Nakajima Y: Clinical significance of CD155 expression in human pancreatic cancer. Anticancer Res 35: 2287-2397, 2015.
34. Qu P, Huang X, Zhou X, Lü Z, Liu F, Shi Z, Lü L, Wu Y and Chen Y: Loss of CD155 expression predicts poor prognosis in hepatocellular carcinoma. Histopathology 66: 706-714, 2015.

35. Bi J, Zheng X, Chen Y, Wei H, Sun R and Tian Z: TIGIT safeguards liver regeneration through regulating natural killer cell-hepatocyte crosstalk. Hepatology 60: 1389-1398, 2014.

36. Baury B, Masson D, McDermott BM Jr, Jarry A, Blottière HM, Blanchardie P, Laboisse CL, Lustenberger P, Racaniello VR and Denis MG: Identification of secreted CD155 isoforms. Biochem Biophys Res Commun 309: 175-182, 2003.

37. Koike S, Horie H, Ise I, Okitsu A, Yoshida M, Iizuka N, Takeuchi K, Takegami T and Nomoto A: The poliovirus receptor protein is produced both as membrane-bound and secreted forms. EMBO J 9: 3217-3224, 1990.

38. Iguchi-Manaka A, Okumura G, Kojima H, Cho Y, Hirochika R, Bando H, Sato T, Yoshikawa H, Hara H, Shibuya A and Shibuya K: Increased soluble CD155 in the serum of cancer patients. PLoS One 11: e0152982, 2016.

39. Mahnke K and Enk AH: TIGIT-CD155 interactions in melanoma: A novel Co-inhibitory pathway with potential for clinical intervention. J Invest Dermatol 136: 9-11, 2016.

40. Nagumo Y, Iguchi-Manaka A, Yamashita-Kanemaru Y, Abe F, Bernhardt G, Shibuya A and Shibuya K: Increased CD112 expression in methylcholanthrene-induced tumors in CD155-deficient mice. PLoS One 9: 112415, 2014.

41. Lozano E, Dominguez-Villar M, Kuchroo V and Hafler DA: The TIGIT/CD226 axis regulates human T cell function. J Immunol 188: 3869-3875, 2012.

This work is licensed under a Creative Commons Attribution-NonCommercial-NoDerivatives 4.0 International (CC BY-NC-ND 4.0) License. 